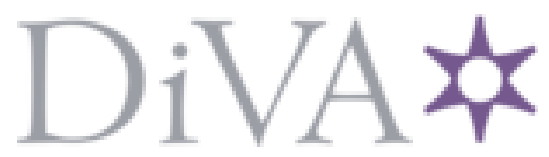

http://www.diva-portal.org

This is the published version of a paper presented at 3rd CIRP International Conference on Industrial Product Service Systems, IPS2 2011 - Functional thinking for value creation.

Citation for the original published paper:

Isaksson, O., Larsson, T., Johansson, P. (2011)

Towards a framework for developing product/service systems.

In: Braunschweig, Germany: Springer

N.B. When citing this work, cite the original published paper.

Permanent link to this version:

http://urn.kb.se/resolve?urn=urn:nbn:se:bth-11241 


\title{
Towards a framework for developing product/service systems
}

\author{
Ola Isaksson ${ }^{1,2}$, Tobias C. Larsson ${ }^{2}$, Pär Johansson ${ }^{1,2}$ \\ ${ }^{1}$ Volvo Aero Corporation, 46881 Trollhättan, Sweden \\ ${ }^{2}$ Luleå University of Technology, 97187 Luleå, Sweden
}

\begin{abstract}
Increasingly, manufacturers become service providers rather than product providers. In this work, a framework based on industrial studies is suggested for developing product service system. The framework is represented by five life cycle phases where three actor categories views are represented. The framework is described using examples from different industries/businesses. The intention is that the framework can be used for both B2C and B2B type of relations. One significant characteristic is that the "traditional" sales phase is replaced by a sales occasion that occur within different life cycle phases depending on which business context/model is used.
\end{abstract}

Keywords:

Product/Service Systems, framework, development, life-cycle

\section{INTRODUCTION}

One effect of introducing the notation of Product/Service Systems (PSS) solution is the change in responsibility and roles the various stakeholders have, and there is a need to facilitate this shift in working conditions. The aim in this paper is to present a framework that facilitates the common understanding of PSS development for both the providers and the users of these solutions.

There is a direct link between products (what is used) and services (how it is used). Their development, however, is not always well coordinated. There are several aspects that make co-development of products and services difficult. One aspect is how products are developed and manufactured. The prevailing paradigm states that the product is developed based on a trade-off between function (including appearance etc.) and the cost of realization. Although life cycle cost is referred to as a mechanism to integrate products and services - user perspective is not explicitly included. A second aspect is how supply chains are integrated. A product is seen as a physical artefact where hardware, and software, is build from components and sub-systems to work together as a system. Products are seen as systems built of components, sub-systems or simply by material ordered from suppliers. This view works for hardware, but is less suitable for services due to its intangible nature. $A$ third aspect is the relation between the manufacturer and the user and customer. Service literature emphasize that the discrete device is one of several elements in strategic relationships [1] hence putting the customer relationship before "requirements" that more relate to the product paradigm. This is because services are activities in collaboration with customers. Product development literature points out how the product is first settled and then services take form to complement that thing [2]. In engineering industry the word "aftermarket" is commonly used to describe the life of a product after it has been designed and developed, while also indicating that a service perspective comes in second place for engineering and manufacturing firms [3]. It can be argued that the value carrier for the customer is either the product or the service provided. Customers however tend to view their purchase from a more holistic perspective [4]. This difference in perception is one reason why in the last decade, the vision for manufacturing industry is to provide their customers with functional offers, meaning that what is sold is the function or the use of the product [5]. Manufacturers are becoming service providers, and as a first step the focus has been put on service provision solely, and not on the combination of services and products.

In this paper we accept the integral view of a Product Service System and focus on the question of how an integral solution can be developed. The potential if the product, and its accompanying services, can be co-developed is significant.

\section{METHOD FOR DATA GENERATION}

The research builds on empirical data from, primarily, aerospace manufacturing companies, and secondly from manufacturing industry. The data has been generated by studying internal documents, deliverables in projects and from experiences in industrial projects. Data has also been generated by applying a participative action research approach [6]. The empirical data set has been analysed in reference to literature studies on product/service systems, and its likes.

\section{THEORETICAL FRAMEWORK}

The theoretical framework builds on three parts, namely some principles of product development, service development, and product/service systems.

\subsection{Product development}

Product Development is typically developed in a process, finding solutions to requirements that have been defined based on understanding customers/market needs. In general, a product development process composes of a number of sequences, going from early design phases to the launch of the discrete device [2]. Today, most models emphasize an integrated, parallel or concurrent approach - integrating functions within the organisation [7]. Also, the importance of iterations is stressed on in these models. Product development models are focused on integrated models to define and produce "a thing" and the customer relation 
comes in as "establishing requirements" and alike.

Today, commonly, a product lifecycle perspective is important to take environmental design aspects into consideration. Thus, a circle-shaped form can symbolize, for example, that taking care of and/or reduce the waste is vital. In such models, the phases recycle, delivery of the product, its maintenance and its use are visualized as additional aspects to consider (see Figure 1).

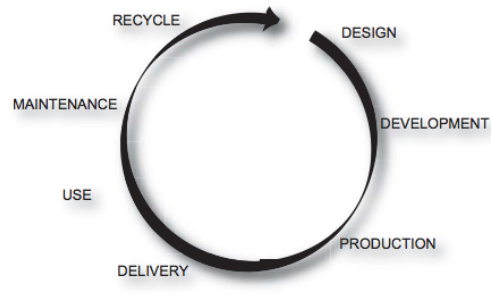

Figure 1. A product life-cycle.

One firm's capabilities and competences are not enough to take care of all lifecycle aspects of a product. For example, taking responsibilities for the products impact on environment, e.g., chose material and production methods with respect to their ecofriendliness, can be done within the manufacturing company. And, for example, recycling is provided by another company. So, at the same time, the picture of several companies working together cross-company is starting to evolve in the models, hence the development of "spiral models" that are increasingly inspiring "traditional" product development models [9].

\subsection{Service development}

For service development, visualization of process models becomes problematic since services are partly produced by the customers and regarded as activities [1]. In this sense, services are partly intangible and unfold in relationships, i.e., people interacting with each other to achieve a goal. Due to this interaction the users are co-producers in services, thus also have an effect on the outcome. Therefore, the customer's own processes are part of the service concept and affect the quality of the service. For example, if maintenance on a machine is planned together with the customer to not interrupt their production, the customer will probably be more content with the service. So, the goal of service development is to make up the conditions for the right customer outcome [10].

A service offer is built upon three main development components, namely, a service concept, a service process and a service system. The service concept describes the customer needs, and links these to how the service should fulfil them. Since partners and customers are co-producers in a service process, they are included to some extent in the model (see Figure 2).

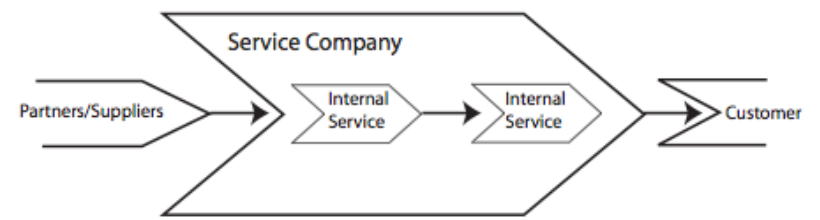

Figure 2. Service process, after Edvardsson [10].

Within the service company the internal services (middle of Figure 2) shows that a service perspective is used throughout the whole process. The internal organizational functions should also be seen as a supplier-customer relationship. A service is always seen from a customer point of view [1], meaning that suppliers should take the perspective of their customer. In service literature $[10,11]$ the customer is a central actor in service provision.

A manufacturer, adopting the service paradigm must, first together with customer's change their way of communicating needs, from specifications to communicating effect of its use. Also, the supplier or the manufacturer has to have a successful way to find the basic needs in these expressions. Second, the organization has to adapt a service perspective. This highlights that, for example, having a product structure might be a barrier. A product structure can prompt people to regard the company as a provider of those specific things. Third, the culture has to change into a service culture. A simple interpretation of this is that all connections and relationships should be seen from a customer point of view, no matter if they are internal or external. A culture can be described as the result of different actions over a long period of time, thus cannot be instilled over night nor fully managed [12]. For a firm focusing on producing excellent goods and provide additional services to complement those devices, the cultural change will be a really challenging issue. This is particularly true, if the development processes are firmly focusing on the commodity as the main carrier for customer value and services are, more or less, something developed haphazard.

The physical resources (middle row at right in Figure 3 ) are from a service perspective focusing on the equipment, premises, technical systems etc. [11]. From a service perspective this means that all actors' resources are included in the production process, e.g., partners, suppliers, customers and so forth.

\subsection{Product/Service Systems}

A PSS business firm is enforced to understand services, use and performance in a more holistic way than in a classical product situation. As denoted in the PSS concept, the products and services have the companionship of 'systems'. Already in 1968 Ludwig von Bertalanffy [13] stated that the concept systems had become popular in all fields of science and made its way into popular thinking, jargon and mass media. The word system can be used to label all sorts of systems, a software application can be a system, the roads and traffic signs are systems, and the laws and regulations in a society are yet another system. These different systems cannot build up the same system, therefore the interfaces between systems, that is how they are linked and how they have an effect on each other is an important issue for understanding wholes [14]. In a system view, treating products and services jointly, we get what is commonly called a Product/Service-System offering, and it can be described as a special case of servitization [15]. Fransson [5] has developed a model for how the service degree increases in engineering firms, calling such offerings "functional offers". A functional offer starts from a traditional product perspective where the discrete device is supported by services (at bottom left in Figure 4). In the next degree of functional offerings, the service part is extended with services that are not usually offered, e.g., customized offerings of expertise from production processes. Then, there are two middle degrees of offerings which put forward that the shift towards a service perspective change how the customer is invoiced, i.e., the engineering firm is paid on the basis of the performance of the device including some services, and at the next degree, all services are included. Here, the sharing of responsibilities to uphold the functionality of the device also comes into play.

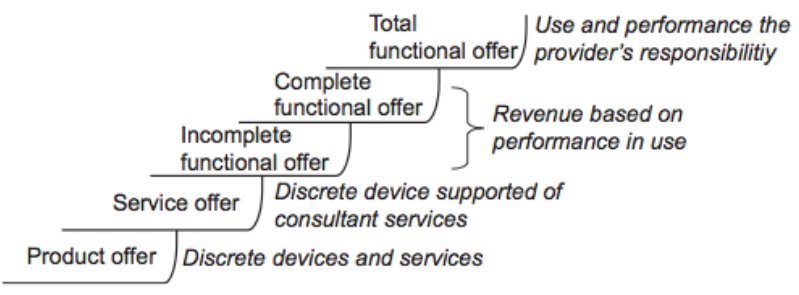

Figure 4. A progress model for functional offerings, after Fransson [5, p.128]. 
Obviously, taking on functional offerings including all services insists on collaboration beyond your company's competences. These kinds of business models are suggested to incorporate an organizational structure of a virtual enterprise, i.e., where the collaboration takes place cross several company boundaries [16] There are challenges to realize PSS and provide successful functional offerings, for example, to understand the voice of the customer more profoundly than merely obtaining the requirements [17] and, to implement an innovation approach there is both internal and external issues to tackle [18]. These examples illuminate that additional capabilities besides the classical engineering ones are part and parcel of developing products for a successful PSS offering. Yet, if the challenges can be handled the advantages abound. For instance, the collaboration in PSS development are expected to reduce some competition through making the business relationships more stable [19], also, PSS triggers changed use patterns that reduces the waste, i.e., provides for ecological sustainability [20,21].

Today, engineering firms state that they continuously on an everyday basis deal with innovation due to developing products; however such innovation is focusing on, e.g., new features on a known endproduct, here called incremental innovation. As discussed above, classical product development seems delimited when it comes to manage and progress innovation in view of PSS. That is such innovation that ends in breakthrough products, here called radical innovation. A radical innovation situation has similarities with wicked problems [22], where several aspects are vague and not fully understood, e.g., What is going to be designed? What should it do? Who is going to use it? And, in what circumstances? [23]. To deal with these questions the design task needs to be addressed from different point of views, i.e., multiple perspectives

For various development projects, distinct process models give the team guidance for how to begin and proceed, as well as pointers to what is needed to fulfil their missions. These processes, whatever they intend to finally produce, are vital. Also, there is a link between industry and applied research, to develop better products and to become better designers; the processes must be continually improved [24]. This motivates engineering design researchers to study them. Process models are not blueprints of reality; rather they are representations of the design world to deal with the relational complexity in the processes. In view of this, the models depend on how the team's actors interpret and perceive them [25].

\section{INDUSTRIAL CONTEXT}

Increasingly manufacturers integrate services close to their product offer and this requires the involvement of customers and actual users of the intended service. The drivers to combine products and services are several, four of these listed in Table 1, where the consequence from a manufacturers point of view is highlighted.

\begin{tabular}{|l|l|l|}
\hline $\begin{array}{l}\text { Drivers towards } \\
\text { PSS solutions }\end{array}$ & Description & $\begin{array}{l}\text { Consequence for } \\
\text { manufacturers }\end{array}$ \\
\hline Regulations & $\begin{array}{l}\text { Regulations that enforces } \\
\text { produces through life/end-of- } \\
\text { life responsibility of } \\
\text { products. }\end{array}$ & $\begin{array}{l}\text { Responsibility after } \\
\text { delivery increases. }\end{array}$ \\
\hline Competition & $\begin{array}{l}\text { Services that tied to the } \\
\text { product and based on } \\
\text { product knowledge, can be } \\
\text { seen as a differentiator on } \\
\text { the marketplace. }\end{array}$ & $\begin{array}{l}\text { Opportunity to add value } \\
\text { for customers. }\end{array}$ \\
\hline Life Cycle Cost & $\begin{array}{l}\text { Increasingly - the cost of } \\
\text { ownership, total cost and life } \\
\text { cycle cost are considered by } \\
\text { the user. }\end{array}$ & $\begin{array}{l}\text { Userincreasingly value } \\
\text { what the products do, } \\
\text { rather that what they are }\end{array}$ \\
\hline $\begin{array}{l}\text { Business Cycle } \\
\text { Management }\end{array}$ & $\begin{array}{l}\text { Users/custerers as a } \\
\text { group may choose to } \\
\text { either maintain or buy } \\
\text { new depending on the }\end{array}$ & $\begin{array}{l}\text { Dynamics of sales } \\
\text { volumes of products may } \\
\text { be balanced through life } \\
\text { cycle services. }\end{array}$ \\
\hline
\end{tabular}

Table 1. Drivers towards PSS.
Another industrial context that is of importance to define as we continue is the similarity and difference between Business to Business (B2B) and Business to Consumer (B2C) markets. In the Business to Consumer situation, the role of the user (consumer) is apparent. The user pays for a service, as he/she enters a contract. A relevant example is mobile phones, where the user can choose between a large variety of service offers. He/she may choose to buy a phone, and pay per use. Alternatively, he can pay a larger fixed cost and lower cost per consumer phase. Under certain conditions he/she can get "free" calls for instance between members of a group or within the operators network. The variety in business models seems endless. The point made here is that in the B2C situation, user behaviour is evident and directly possible to relate to the product, and the product/service offer. Manufacturers of phones (enablers) may choose to focus on the product, or integrate the product with service functionality within the platform. In the B2B case there are several reasons why the relations between the user/customer and manufacturer differ from the B2C case. The actual end user is not always the same as the one who pays for the classical product. An example is that the passenger (user) that buys a ticket from a bus-company or an airline. He/she pays for the service. The transportation company (airline, bus company etc.) buys the bus, or aircraft from a manufacturer. In this case the B2C relation between Passenger and User relates to the service whereas the Bus company buys the product, or the combined product-service system from a manufacturer. These have a B2B relation. Also, in $\mathrm{B} 2 \mathrm{~B}$ relations the actual person, or group of persons involved in the negotiation about requirement on the product are specialists and seldom themselves users of the resulting product.

For services - user involvement is decisive. There is most often several steps between the user and the manufacturer. If the manufacturer now increasingly offers services - who is then the user? If user behaviour is tightly coupled with value and service consumption the identification of user, and the involvement of users, need special consideration. In the B2C case the understanding and involvement of users is more evident, since the customer and the user are the same. Involving the customer is the same as involving the user. In the B2B case, involving the customer is quite relevant since the agreement of what has to be developed has to be agreed between the business partners. From a service perspective - the end user may use the service.

Based on the observations and arguments presented, we argue that there exists an imbalance between the drivers to provide integrated product-service system solutions and the coordination of capabilities to develop such solutions. Primarily the way services and products are developed are not as integrated as needed.

Four topics can be highlighted as critical for developing integrated product-service solutions. First - a clear link to the environment of consumption of the service, i.e. how and what users do, and how current user conditions area. Experience and skills in User operation is critical. Secondly, to design a solution, the forthcoming solution need to be possible to describe, model and understand. Modelling the service attributes is another area. Third, since products are developed in one way, and services typically in other ways, their integrated PSS development procedure is another key topic. A fourth topic is the understanding of PSS as such. A common understanding in-between the actors active in developing and providing integrated products and services is crucial.

An assessment of basic capabilities, current best practices and future state of the art capabilities is summarized in Table 2 . 


\begin{tabular}{|l|l|l|l|}
\hline Topic facet & Basic Capability & $\begin{array}{l}\text { Current best in class } \\
\text { capability }\end{array}$ & $\begin{array}{l}\text { Future state of the art } \\
\text { capability }\end{array}$ \\
\hline $\begin{array}{l}\text { Experience from } \\
\text { Use/Operate }\end{array}$ & $\begin{array}{l}\text { Feedback, Continous } \\
\text { improvement, Lessons } \\
\text { Learnt }\end{array}$ & $\begin{array}{l}\text { Continous update of best } \\
\text { practice } \\
\text { /lnstruction/Processes }\end{array}$ & $\begin{array}{l}\text { Methods/Tools that } \\
\text { include service } \\
\text { restraints/experiences into } \\
\text { design methods/tools }\end{array}$ \\
\hline $\begin{array}{l}\text { Modeling Service } \\
\text { Attributes }\end{array}$ & $\begin{array}{l}\text { Business Modeling,Cost } \\
\text { modeling, ABC }\end{array}$ & $\begin{array}{l}\text { Account for operation } \\
\text { conditions for design } \\
\text { (MTBF etc). LCC based } \\
\text { design }\end{array}$ & $\begin{array}{l}\text { Possible to "Design" } \\
\text { Service attributes }\end{array}$ \\
\hline Integrated PSS \\
development & $\begin{array}{l}\text { "Concurrent Engineering" } \\
\text { roles involved early on }\end{array}$ & $\begin{array}{l}\text { Customer/user } \\
\text { involvement in start/spec } \\
\text { and Evaluation of } \\
\text { solutions - Open } \\
\text { Innovation oriented work }\end{array}$ & $\begin{array}{l}\text { Enterprise development } \\
\text { that includes the all roles } \\
\text { user, provider and } \\
\text { enablers }\end{array}$ \\
\hline Understanding of PSS & $\begin{array}{l}\text { Sell products together with } \\
\text { services }\end{array}$ & $\begin{array}{ll}\text { Design products so these } \\
\text { can be used for services }\end{array}$ & $\begin{array}{l}\text { New competence mix } \\
\text { required. }\end{array}$ \\
\hline
\end{tabular}

Table 2. Basic, Best Practice, and Future capabilities.

\section{A FRAMEWORK FOR DEVELOPMENT OF PSS}

The main purpose of the framework is to enable a common tool for co-develop product service systems, facilitate communication and understanding of the concepts emerging.

\subsection{Framework roles}

First we focus three complementary roles useful when forming the framework for developing product service systems. We choose to use only three roles, the User, the Provider and the Enabler, see Figure 5.

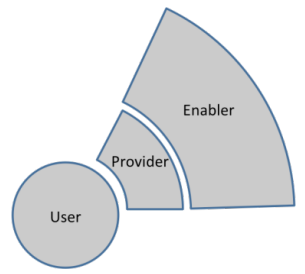

Figure 5. Framework roles

The roles presented have all different views on the solution.

The User is a consumer of the PSS. Example: Passenger in an aircraft, user of cell phone or a professional user such as an airline (service provider).

The Provider is the organization responsible to offer the integrated PSS solution. The provider has direct relation to the user.

The Enabler is a collective term for organizations providing technologies or services necessary for the provider to provide solutions.

All actors within the PSS system should be possible to map onto one of these roles.

\subsection{The PSS solution}

The notation used for the relation between Need, Solution and the Solution components is seen in Figure 6.

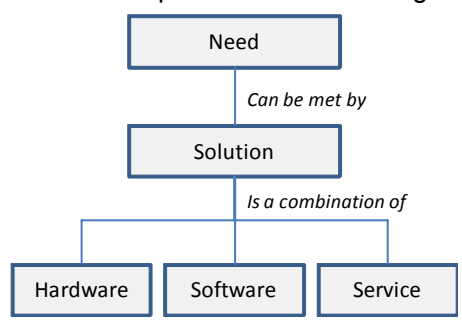

Figure 6. Relation between Need, Solution and Solution Components.

The hierarchy states that the solution is a combination of Hardware, Software and Services.

\subsection{Life-cycle phase model}

Secondly, we introduce a simple, generic life cycle model that can be applied to products, services and its combination.

\begin{tabular}{|c|c|c|c|c|}
\hline Need Phase & $\begin{array}{l}\text { Solution } \\
\text { seeking }\end{array}$ & \begin{tabular}{|l} 
Solution \\
Development
\end{tabular} & \begin{tabular}{|l} 
Solution \\
Realization
\end{tabular} & \begin{tabular}{|l} 
Solution \\
Support
\end{tabular} \\
\hline
\end{tabular}

Figure 7. A five-phase life-cycle model.

The life cycle phases are generic in the sense that both typical product development processes and service development processes can be mapped onto the process. Each phase is described below.

Need Phase: The need phase is where there a user has a need. The phase is also applicable where there is an idea of a solution to a need that few users are aware of. In the latter situation there is a marketing work to "Create" a need.

Input to the need phase can be a decision of a strategic move for a company to offer new, or improved functionality in a market, or simply a solution that has some limitations or restraints that omit the user to perform as desired.

Output from the need phase is an identified need, opportunity or idea, that is defined to the extent that a solution can be sought after.

Solution Seeking: The solution seeking phase is characterized by search for existing solutions, alternative solutions, sub-solutions etc. that may be possible to use. This phase is equivalent to Predevelopment, Conceptual development or technology development in traditional product development processes.

Input to the Solution seeking phase is the identified need, opportunity of idea, generated in the Need Phase.

Output from the Solution phase is the conceptual solution. The solution mix is identified, where a part of the solution may require physical products and software, other parts of the solution may be suitable to be met by a service.

Solution Development: The solution development phase is the coordinated development of PSS components. The solution development phases may include a "traditional" product development process for developing the physical part of the solution. Co-ordination with service development is needed. The important aspect is that the service is developed in parallel with the product, allowing enabling technologies/solutions necessary for the intended service can be supported by features in the product.

Input to the Solution Development phase is solutions identified in the Solution Seeking phase.

Output from the Solution Development phase are solutions that offered to customers.

Solution Realization: This is the most intriguing phase. Solution realization in traditional hardware terms is the manufacturing and delivery of the product. The realization of services is the actual use event, i.e. a repair activity, a training activity or the bus driver, driving the bus

Input to the Solution Realization phase is the defined ProductService offer.

Output from the Solution Realization phase is the actual provision of the product-service system. Notably, the deliverable of a physical product to be used in a product-service system is a partial delivery of the offer. The consumption of a training activity (example) is a part of the realization phase.

Solution Support: The solution support phase represent the change in state of a product-service offer. New technologies such as upgrades of existing, or offer of new, software is a part of the Solution support phase. 
Input to the Solution Support phase is that there exists a provision of a product-service system.

Output from the Solution Support phase is a changed state of the product-service system.

\subsection{Combined framework model}

Following one of the principles behind the Zachman Framework [26] for architecting information systems, the views of each role are introduced into each life cycle phase. The viewpoint of each role in relation to the evolvement of the PSS solution can be expressed.

Notably, there is no explicit «market» phase or «sales» phase. Nor is there an aftermarket phase. This is a necessity since the "sales» occasion differ depending on what business, or what solution strategy is being developed. In the model, the sales occasion is represented as a marker - that is positioned in different phases, see Figure 8.

\begin{tabular}{|c||c||l|l|l|}
\hline Need Phase & $\begin{array}{l}\text { Solution } \\
\text { Seeking }\end{array}$ & $\begin{array}{l}\text { Solution } \\
\text { Development }\end{array}$ & $\begin{array}{l}\text { Solution } \\
\text { Realization }\end{array}$ & $\begin{array}{l}\text { Solution } \\
\text { Support }\end{array}$ \\
\hline \hline Users view & Users view & Users view & Users view & Users view \\
\hline \hline Providers view & Providers view & Providers view & Providers view & Providers view \\
\hline \hline Enablers view & Enablers view & Enablers view & Enablers view & Enablers view \\
\hline
\end{tabular}

Figure 8. The sales occasion is variable.

\section{DEMONSTRATION OF FRAMEWORK USAGE}

In this section we introduce the proposed framework by an example. The example used is an illustrative situation labelled a Product Availability optimization offer in the aerospace business.

The case is described as follows:

The professional user in this case is an airline, providing travel services to end end-users (passengers). The provider is a productservice system provider in the aeronautical sector, which is providing an availability service together with its core product as an OEM. As we shall see the PSS provider enterprise actually forms as a part of the development process.

In the case we make the assumption that the "always on time» strategy has been analysed initially by the airline which concluded, amongst others, that availability and turnaround time for clarifying the engine was one critical factor for success.

Enablers are several such as the hardware enabler (gauges) and a service enabler (repair) and a transport logistics provider.

A walk through of the development using the framework follows as;

Need Phase: Passengers value timeliness and reliability for the travel service. An airline has chosen to use «always on time» as the differentiator on the market. The work starts with framing the consequences and expressing needs. One of the identified needs is the timely availability of carriers, and a pre-defined way of dealing with unexpected incidents with inspections and unplanned maintenance. Limiting the example to availability of ready-to-use engines, the airline, together with the engine manufacturer and engine overhaul services identifies the need for a solution that covers several areas, including condition based maintenance, training of clarification personnel and repair methods. In addition, the solution must also include solutions to compensate for potential delay situations - yet ensuring schedules for passenger to be on time. The user value for the passenger is timeliness, and for the airline availability of equipment and a service to overcome unintended problems.

\section{Solution seeking phase}

The Solution seeking phase identifies that a mix of services and product features are needed. Several actors in the solution chain need to collaborate to find a solution.

As a result from a workshop between representatives from the airline together with the aircraft and engine representatives, ideas are identified for how to provide solutions that can beet the challenge to ensure «always on time». A virtual company is seen as an option where several different actors collaborate to offer the product/service system solution.

There are several solution strategies identified, amongst them

- A travel logistics service, requiring more accurate engine condition data

- A condition monitoring tool, capable of providing data to the logistics service

- Data logging and analysis tools to feed the condition monitoring system

- Data measuring and acquisition, with more accurate data provision

- Engine control features, enabling «safe operation » modes despite some, non-flight worthiness critical, incidents

- A number of less engine coupled services ensuring timeliness for travellers requiring the involvement of ATM (Air Traffic Management) actors etc.

All together the entire solution require the joint effort of a number of actors,

In the Solution realization phase an enterprise is formed including the actors who share risk and revenue of providing the service to the airline.

Development of software, service and hardware is co-ordinated within the enterprise. The engine is equipped with dedicated integrated sensors, enabling real-time diagnostics required for the high performance condition monitoring system. In turn the condition monitoring system enables the desired combination of condition based maintenance with the logistic planning service that need to be available in real time. These solutions are co-developed and aligned with then needs of the service solutions.

The engine manufacturer has knowledge about the engine and its certified flight safety capabilities. This knowledge is combined with the actual condition to - in real time - analyse the most common incident conditions and make engine control system regulation solutions as time constrained solutions. The result is that the engine state can be instantly and correctly analysed, and included in dynamic planning for the airline. Simultaneously the airline and the transport logistic services take advantage of the extended condition monitoring system that together increase availability of the engine service, despite disturbances. Also the flight logistics service provision has developed agreements with other parties to complement the more technical achievements in the solution, such as a software company who develops and supports the tool for airline personnel.

Finally, in the solution support phase, there is a contractually agreed solutions improvement program where adjustments and improvements to all constituent PSS components are introduced. The providing enterprise may include new partners to meet updated needs. Out of Scope improvements are offered as new functionalities, or up-graded functionalities, whereas incremental solutions, of win-win- type are introduced continuously. 


\section{DISCUSSION}

It can be argued that this scenario is already happening in real life. All services and technologies in the story may exist, but the integrated perspective is rarely seen. Why?

At first, the manufacturer in the scenario had to use solutions mainly indented to be used for internal purposes. The algorithms needed to offer the advanced condition monitoring service to a customer, was based on internal know how. The externalization of such capabilities require another dimension - the packaging and provision of such algorithms in a commercially used end user IT system. Internally, it was used within the engineering organization and never intended for commercial use. In the case - a liaison with a professional IT vendor was a must.

Secondly, the scenario might have been the result of an "open innovation" effort, i.e. the solution was not apparent within a single organization. Despite the power of open innovation, the full penetration is not yet seen in established organizations.

Third, there is the problem of timing. All parties in the scenario must be ready, technically, mentally and business wise to address risk and revenue aspects.

Finally, what is essentially addressed here, is that there is a need for a communication and development tool, that enables service development and product/technology development to co-happen; the proposed framework.

It is argued that the framework enables the necessary dialogue between the partners co-acting to offer a combined product-and service solution, where the actual organization to realize the solution does not necessarily pre-exist.

For further work the suggested framework will be further defined and validated with case studies from different industries. The framework can also be used as a reference model to associate specific tools, such as enterprise modelling and value modelling and simulation tools.

\section{ACKNOWLEDGMENTS}

The financial support from SSF (Swedish Foundation for Strategic Research) through ProViking research programme, and from VINNOVA through the Faste Laboratory is gratefully acknowledged.

\section{REFERENCES}

[1] Grönroos, C. (2000): Service management and marketing: a customer relationship management approach. Wiley, Chichester.

[2] Ulrich, K.T., Eppinger, S.D. (2008): Product Design and Development. McGraw-Hill, Inc.

[3] Normann, R. (2001): Reframing business - when the map changes the landscape. Chichester: John Wiley \& Sons Ltd.

[4] Mello, S. (2002): Customer-centric product definition: the key to great product development. Boston: USA: AMACOM.

[5] Fransson, M. (2004): Verkstadsindustrins tjänstefiering - en explorativ resa i det nya affärslandskapet (in Swedish). Licentiate thesis. CTF, Karlstads Universitet, Sweden, No. 2004:24.

[6] Stringer, E.T. (1999): Action Research, 2nd ed. Thousands Oaks, Sage Publications Inc, CA.

[7] Andreasen, M.M. and Hein, L. (1987): Integrated product development. Berlin, New York: Springer-Verlag.

[8] Ullman, D.G. (2003): The mechanical design process. 3rd ed. New York: McGraw-Hill.
[9] Unger, D., Eppinger, S. (2010): Improving product development process design: a method for managing information flows, risks, and iterations, Journal of Engineering Design, pp 1-11.

[10] Edvardsson, B. and Modell, S., eds. (1996): Service management. interdisciplinary perspectives. Stockholm: Nerenius \& Santérus Förlag.

[11] Edvardsson, B., Johnson, M.D., Gustafsson, A., Strandvik, T. (2000): The effects of satisfaction and loyalty on profits and growth: products versus services. Total Quality Management, 11, vol. 7.

[12] Grönroos, C (1996): Service culture, perceived service quality and their marketing impact. In Edvarsson, B. and Modell, S. Editors. (1996). Service management: interdisciplinary perspectives. Nerenius \& Snatérus Förlag AB, Sweden, 113122.

[13] von Bertalanffy, L. (1968): General System Theory: Foundations, Development, Applications. George Braziller, NY, USA.

[14] Checkland, P., Holwell, S. (1998): Information, Systems and Information Systems: making sense of the field, Wiley, Chichester.

[15] Baines, T.S., Lightfoot, H.W., Evans, S. et al. (2007): Stateof-the-art in product-service systems, in: Proceedings of the Institution of Mechanical Engineers, Part B: Journal of Engineering Manufacture. Vol. 221, No. 10.

[16] Johansson, C., Larsson, A., Larsson, T. \& Isaksson, O. (2008): Gated Maturity Assessment: Supporting Gate Review Decisions with Knowledge Maturity Assessment. CIRP Design Conference 2008. Twente, Netherlands.

[17] Ericson, A. (2007): A need-based approach to product development. Thesis (PhD). Luleå University of Technology, No. 2008:01, ISSN 1402-1757.

[18] Parida, V. (2008): Challenges in Open Innovation Practices for Industries. Nordic Innovation Research - NIR 2008, nr 3. December 8-9 2008, Oulo, Finland.

[19] Alonso-Rasgado, T., Thompson, G., Elfström, B-O. (2004): The design of a functional (total care) product. Journal of Engineering Design, 15 (6): 515-540.

[20] Mont, O.K. (2002): Clarifying the concept of product-service system. Journal of cleaner production 10: 237-245.

[21] Mont, O., Dalhammar, C., Jacobsson, N. (2006): A new business model for baby prams based on leasing and product remanufacturing. Journal of Cleaner Production, 14: 15091518.

[22] Rittel, H. and Webber, M. (1973): Dilemmas in general theory of planning. Policy Sciences, 4, 155-169.

[23] Randall, D., Harper, R., and Rouncefield, M. (2007): Fieldwork for design - theory and practice. London: SpringerVerlag.

[24] Dubberly, H. (2009): How do you design? A Compendium of Models. Working paper. Dubberly Design Office, San Francisco, CA, USA.

[25] Engwall, M., Kling, R. \& Werr, A. (2005): Models in action: how management models are interpreted in new product development. R\&D Management, 35(4), 427-439.

[26] Zachman, J. (1987): A framework for information systems architecture. IBM Systems Journal, Vol 26. No 3. 